\title{
Nursing risks and preventive strategies of the elderly: an interview-based study with staff at long- term care facilities
}

Chang-qing Liu

Sichuan University

Hong-fei Ren

Sichuan University

Jia-ling Li

Sichuan University

Li-nan Cheng

Sichuan University

Xiao-feng Xie

Sichuan University

Feng-ying Zhang ( $\triangle$ lcqing915@126.com )

Sichuan University

\section{Research Article}

Keywords: long-term care facilities, nursing risk, risk-related factors, preventive strategies, qualitative study

Posted Date: February 17th, 2022

DOI: https://doi.org/10.21203/rs.3.rs-1305907/v1

License: (9) This work is licensed under a Creative Commons Attribution 4.0 International License. Read Full License 


\section{Abstract}

Background: The prevention and control of nursing risks play a critically important role in ensuring safety and maintaining the health of the elderly in long-term care facilities.

Methods: In-depth interviews were conducted on participants in 16 long-term care facilities using a semistructured interview. The transcribed interviews and field notes written during the visits were analyzed inductively following a constant comparative method as described in Grounded Theory. Data were analyzed using framework analysis and domains, and the NVivo 10 software was used to refine themes and build relationships among themes. The authors followed the COREQ guidelines to ensure rigour in the study.

Results: A total of 28 participants (18 managers, 5 head nurses, 2 qualified nurses, and 3 healthcare assistants) were interviewed. In the risk warning model, nursing risks (factors that affect risks, consequences), risk early warning intervention measures (risk assessment, training, and education, comprehensive preventive measures), challenges and solutions as potential and observation variables affecting nursing risks, were aimed to reduce nursing risks in long-term care facilities.

Conclusions: There are many nursing risk factors in long-term care facilities, among which nursing risk assessment plays an important intermediate role in risk prevention. Comprehensive measures can be formulated and implemented according to relevant nursing risk factors, referred to as the early warning model, to reduce the incidence of nursing risks and promote the safety of the elderly in long-term care facilities.

\section{What Is Already Known}

- Nursing risks are usually avoidable, but continue to be problematic especially in older populations in long-term care facilities.

- Little is known about the barriers and facilitators to nursing risk prevention in long-term care facilities.

\section{What This Paper Adds}

- Nursing risks in long-term care facilities are affected by related factors and can lead to adverse consequences.

- The early warning and interventional measures of nursing risks mainly include risk assessment, training and continuing education, and comprehensive risk prevention measures, etc.

- Nursing risk assessment plays an important intermediate role in nursing risk prevention and control in long-term care facilities. 


\section{Background}

With an increasingly aging population in China, the number of disabled and semi-disabled elderly people continues to rise. With changes in family structure, lifestyle, and habits, the burden of family care increases, as a result of which long-term care facilities that provide comprehensive services such as life care and geriatric nursing for the elderly, play an increasingly important role. Hence, more elderly people, who are unable to live independently, and their families choose long-term care facilities for continued care to relieve themselves of their burden of care. However, safety is the primary concern of the elderly living in long-term care facilities ${ }^{1}$. Research ${ }^{2,3}$ has shown that the main nursing safety concerns in long-term care facilities are falls, suffocation, getting lost, medication errors, pressure ulcers, etc. Of these, pressure ulcers are key quality indicators of clinical care. A higher incidence of pressure ulcers, between $11.9 \%^{4}$ and $23.2 \%^{5}$, has been reported in nursing homes.

The elderly are characterized by poor overall health status, decreased cognitive function, and relatively high risk of death, and they are a group with a high incidence of nursing risk events ${ }^{6}$. Nursing risk management of long-term care facilities, analysis and evaluation of service process risk factors, an increase in awareness of risk prediction, and reduction of nursing process risk factors, are all conducive to the provision of better quality and safety of nursing ${ }^{7}$. For instance, a targeted care strategy that improves staff connections, information flow, and the use of cognitive diversity in clinical problemsolving can increase the implementation of an evidence-based fall prevention program that can improve health outcomes for the elderly ${ }^{8}$. To facilitate the adoption of evidence-based guidelines in healthcare, care staff can be the potential targets for behaviour change interventions ${ }^{9}$. Therefore, improving cooperation, quality, and professionalism among nursing staff are expected to improve safety and the quality of life of the elderly in long-term care facilities.

The prevention and control of nursing risk play an important role in ensuring safety and maintaining the health of the elderly in long-term care facilities. However, the elderly are in the high-risk category of nursing risks in long-term care facilities. To date, there remains a lack of risk prevention and control mechanisms, which is worsened by a lack of knowledge about nursing risks and the factors that affect these risks in long-term care facilities in China. To better care for the elderly, maximize their protection, and explore the components and factors affecting nursing risks in long-term care facilities, research on nursing risks in long-term care facilities within the Chinese pension system is warranted. Semi-structured interviews were conducted to explore existing nursing risks, risk factors and solutions, and promote a culture of safety that would further improve comprehensive care (including life care, medical care, etc.) and safety of the elderly in long-term care facilities.

\section{Methods}

\subsection{Study design}

This is a qualitative interview study with a constructivist approach and exploratory design. 


\subsection{Participants}

Research subjects at long-term care facilities in Chengdu, China (nursing homes and the Geriatrics department of a hospital) were contacted via invitation letters and phone calls. We approached 22 longterm care facilities that had expressed a preliminary interest in participating in our research program. Four nursing homes either did not respond to the researchers or declined due to understaffing, sickness within the management team, and recent participation in research activities. Two other nursing homes were not included in the study after theoretically adequate data was available. Ultimately, 28 participants (18 managers, 5 head nurses, 2 qualified nurses, and 3 healthcare assistants) from 16 longterm care facilities were interviewed and the data were analyzed (Fig. 1). From qualitative analysis, the data obtained from the 28 staff members proved to be adequately rich to reach data saturation, with additional interview responses not yielding any further unique perspectives ${ }^{10}$.

\subsection{Data collection}

A combination of convenience sampling and theoretical sampling was used to obtain the final sample of 28 participants. Convenience sampling was used at the outset of the study. theoretical sampling was used after a conceptual model was established. The researchers contacted the managers of the institutions where the interviewees were employed. The managers then assigned interviewees who voluntarily established contact with the researchers, and an appointment was made for the visit. The sample size was based on data saturation which was assessed using the criteria proposed by Francis et al. $(2010)^{11}$, whereby data collection can cease when no additional codes emerge from three consecutive interviews following the analysis of at least ten interviews.

Face-to-face interviews were conducted at the participants' workplaces. Each interview was approximately 50 minutes in duration and conducted by the same researcher [JL] to ensure consistency. The interviews were audio-recorded, transcribed verbatim, and proofread [LC]. The researchers introduced the purpose and general content of the study to the interviewees and then performed interviews at specified quiet spaces according to the predetermined outline (Table 1). The interview was analyzed by combining the audio recording with the researcher's on-site record. The interviews were digitally recorded with the participants' permission. The recordings were thereafter transcribed verbatim.

\subsection{Data analysis}

We followed the COREQ guidelines to ensure rigour in our study. The interviews were transcribed verbatim and followed the constant comparative method suggested by Grounded theory. The data were managed and analyzed using NVivo 10 . The transcripts were read and initially coded inductively and then deductively, and specific themes and codes were categorized. The data were analyzed inductively to ensure important themes were not lost due to deductive data analysis, and until no new themes were identified during inductive analysis. All transcripts were analyzed by one author [CL] and independently 
reviewed by another author [HR] to ensure the reliability of the coding. Any discrepancies were discussed and resolved, and the content of each code was discussed with all authors.

\subsection{Ethics}

Ethical approval for the study was obtained from the Biomedical Ethics Committee of West China Hospital of Sichuan University (No. 2021-255). Written informed consent was obtained from all participants.

\section{Results}

\subsection{Sociodemographic characteristics of the participants}

Semi-structured, face-to-face interviews were performed on 28 participants from 16 long-term care facilities in Chengdu, China. The ages of the participants ranged from 24 to 60 years (average $41.5 \pm 5.8$ years) and 3 participants were male. The duration of employment ranged from 3 to 39 years, with an average of $13.6 \pm 11.5$ years. There were 5 public long-term care facilities and 11 private long-term care facilities.

\subsection{Risk warning model for nursing in long-term care facilities}

The related nodes of nursing risks and factors in long-term care facilities are as shown in Table 2.

By generalizing, a risk warning model of nursing in long-term care facilities has been developed, which consists of risk identification - risk assessment - risk prevention and control measures - risk early warning. Among them, nursing risks (factors, consequences), risk early warning intervention measures (risk assessment, training and education, comprehensive preventive measures), challenges, and solutions were identified as potential and observable variables affecting nursing risks, with the ultimate goal of reducing nursing risks in long-term care facilities. (Fig. 2)

\section{Discussion}

\subsection{The main nursing risks and factors in long-term care facilities}

\section{(1) Nursing risks}

Falls are the most common accidents among older people in long-term care facilities. (Reference point 1). In our study, 10 long-term care facilities mentioned falls as being an important nursing risk for the elderly. The managers of long-term care facilities should formulate targeted comprehensive health education programs, specifically focussed on the elderly with low educational levels and cognitive impairment. Training includes knowledge of fall prevention, self-rescue after a fall, knowledge of medications, choice of food and posture while eating, skincare methods, early intervention of cognitive impairment, proper use of wheelchairs, etc. A study ${ }^{12}$ that included a total of 1832 residents in Japan 
also showed that falls were significantly associated with an inability to walk or stand up or go to the toilet without assistance, visual impairment, insomnia, and dementia. Furthermore, there are many medications associated with falls among nursing homes residents, such as antiparkinsonian drugs, muscle relaxants, antiepileptics, antipsychotics, antidepressants, opioids, etc. To prevent falls, caregivers should provide adequate care, and healthcare professionals should consider monitoring or management of these medications.

A woman once had difficulty with swallowing and inhalation, which resulted in vegetables being stuck while swallowing (Reference point 5). Therefore, caregivers should pay more attention by accompanying and observing the elderly while they are eating, to avoid choking. The risk of pressure ulcers among the bedridden elderly is higher, which is also a common nursing risk (Reference point 3 \& 4). Frail, older people admitted to nursing homes are at risk of a range of adverse outcomes, including pressure ulcers ${ }^{13}$. Individuals who are most at risk of developing pressure ulcers are those with serious illness, elderly, have impaired mobility, and/or poor nutrition ${ }^{14}$. Effective prevention consists of a set of strategies aimed at reducing the intensity and/or duration of pressure and shear on the tissue and underlying body structures ${ }^{15}$.

\section{(2) Factors affecting nursing risk}

The elderly become frail with age, and their energy and motivation decrease (Reference point 16). Physiological factors, such as lower extremity muscle weakness and functional limitations in gait and balance, have been associated with a risk of falling ${ }^{16}$. Additionally, economic status, social role, and habits of the elderly change with age resulting in psychological diseases. The mental health status of the elderly in institutional care is worse than those in family care, among whom the incidence of depression is $65.52 \%{ }^{7}$. Besides, more than two-thirds of nursing home residents have dementia in high-income countries, and fewer than half of these residents report good quality of life ${ }^{17}$. A study ${ }^{18}$ suggested that these geriatric syndromes (multiple morbidities, cognitive impairment, frailty, disability, sarcopenia, malnutrition, impaired homeostasis, and chronic inflammation) are associated with a risk of hospitalization or nursing home admission, after controlling for the presence of specific diseases. Efforts to prevent nursing risks in long-term care facilities should target strategies to prevent and manage these syndromes.

Managers, nursing assistants, and the elderly and their family members have poor awareness of safety and show negligence in safety risk assessment and management, which may lead to adverse events such as scalds and falls (Reference point 1). Besides, some participantssaid that the main environmental factors for falls are unreasonable infrastructural designs, for example, many long-term care facilities do not install floor lights, provide anti-skid measures, install toilet handrails, etc. (Reference point 3 \& 6).Accordingly, long-term care facilities should be designed to provide a living environment that would help prevent slips and falls to ensure the safety of the elderly. 


\subsection{Risk early warning intervention measures}

\section{(1) Risk assessment}

Multiple scales are often used to comprehensively evaluate the living habits and care of the elderly, and their daily living ability, physical functioning, geriatric syndromes, geriatric health status, long-term care facilities, etc. (Reference point 5). The residents of long-term care facilities typically have a passive lifestyle, as most of the elderly spend their daily lives in a seated or lying position, that results in a lower physical capacity related to balance, walking speed, and aerobic endurance, which, in turn, affects their quality of life ${ }^{19}$. Consequently, performing an exercise regimen that is adapted to the ability and aspirations of the residents of long-term care facilities to increase their physical functioning and self-care ability is necessary.

An assessment of falls from beds mainly includes an elderly's situation, the environment, and equipment, such as whether or not bed bars press on an elderly individual's hands (Reference point 3). The fear of falling leads people to adopt a passive, sedentary lifestyle, that almost doubles the risk of falls. Positive outcomes have been reported, even among the very old and frail, with a 7-week exercise program or a home-based physical training program ${ }^{16}$. There are indications that simple activity or exercise can result in increased balance and physical function among the elderly in long-term care facilities.

\section{(2) Training or education}

New employees should be trained. The training methods are mainly on-site teaching and self-study, and the head nurse supervises and evaluates trainees at regular intervals. Training content includes feeding position, skills, life care, falls, pressure ulcer prevention, etc. (Reference point 3). Most elderly people who live in long-term care facilities suffer from chronic diseases, and a decline in physiological functioning and other factors, leading to a decline in self-care ability, a lack of ability in keeping themselves safe, and a decreased ability to handle emergencies after accidents occur. Chunmei Zha et al. ${ }^{20}$ investigated and analyzed the status quo of nursing safety risk cognition of 221 elderly people in long-term care facilities, and found that the score of nursing safety risk knowledge of elderly people was at a relatively low level, with the score for fall safety cognition being the lowest. Nurses should therefore pay attention to the education of nursing safety risk knowledge of the elderly, and targeted comprehensive health education programs should be formulated to improve nursing safety and risk awareness of elderly people in longterm care facilities, to reduce risks and improve quality of life.

\section{(3) Consequences}

After the occurrence of adverse events, there is great psychological stress on our nurses. Therefore, managers should include care providers while addressing the caregiver-elderly relationship and comforting their families, to avoid the occurrence of new errors after care providers experience excessive stress (Reference point 6). After the occurrence of adverse events, some patients and their families do not understand the situation, which results in medical disputes that require the long-term care facilities to compensate, and affects the performance appraisal of the nursing staff (Reference point 4). It is 
necessary to facilitate and support caregivers continually, to care for the elderly in long-term care facilities.

\section{(4) Comprehensive preventive measures}

Communicating regularly with family members to discuss the current situation and the risk points of the elderly, enhance mutual trust, and obtain family support and care (Reference point 4). Quality control seminars are held every month, case analyses are conducted, and risk responses are planned and processed (Reference point 11). A comprehensive nursing risk management system is an important guarantee in reducing the incidence of choking and asphyxia among the elderly in long-term care facilities ${ }^{21}$ and should help improve and standardize risk management. Therefore, multifactorial interventions should include exercise, balance, strength and gait training, nutritional supplementation, management of medications (especially psychoactive medications), home environment modifications, and management of postural hypotension, vision, foot, and footwear problems. These interventions could effectively decrease falls in the community, hospital, and nursing home settings ${ }^{22}$.

Timely risk assessments of the elderly and the environment are necessary. Risk assessments of the elderly include mental state, physical condition, history of falls, and diet, which should be followed up every day. The environmental risk assessments include lighting, floors, and supplies (Reference point 1). Long-term care facilities should build an environment to prevent falls, such as installing handrails on both sides of urinals, placing anti-slip mats in bathing areas, and keeping floors clean and tidy. Moreover, they should encourage the elderly to choose and wear shoes with anti-skid soles, and choose walking aids appropriately, per the physical conditions of the elderly, and avoid walking within one hour after taking antihypertensive drugs or antidiabetic drugs. Function-based exercise should be a focus for interventions to protect older, high-risk people from falls and to improve and maintain functional capacity ${ }^{23}$. Besides, indwelling devices (e.g., urinary catheters and feeding tubes) are often used by the elderly at nursing homes. Inadequate care of the elderly with these devices contributes to high rates of multidrug-resistant, device-related infections ${ }^{24}$. Therefore, special attention should be paid to indwelling devices and medication safety of the elderly, and there should be close team cooperation to actively assess the physical and mental conditions of the elderly in long-term care facilities, and early warning and prevention should be implemented.

\subsection{Challenges and solutions}

\section{(1) Problems and obstacles}

The quality of nursing staff needs to be further improved (Reference point 1). Lack of human resources for elderly care is the biggest problem at present (Reference point 3). A study has shown that a high workload also results in difficulties attracting permanent staff to long-term care facilities ${ }^{25}$. With high staff turnover, the possibilities of improving nursing quality and reducing nursing risks are diminished, especially due to the unpredictable and often urgent nature of long-term care facilities care ${ }^{26}$.

\section{(2) Solutions}

We need to strengthen the training of existing personnel, preferably by training them abroad. The relative 
cost of recruitment of personnel with seniority and experience is high, hence we should strengthen followup training for those who have been recruited (Reference point 4). In addition, it is necessary to formulate a complete and unified training system among long-term care facilities across the entire country (Reference point 1). A study ${ }^{27}$ has shown that the current employment outlook in long-term care facilities in China is not very optimistic, due to heavy workloads, low professional quality, and low salary levels, causing burnout among the staff. It is suggested that incentive mechanisms of human resources be used to alleviate the current situation. First, reasonably adjusting the working and rest hours of employees is necessary. Second, establishing economic interests as the core of the incentive mechanism, and linking career levels with promotion need to be implemented. Third, job-related tasks need to be enriched and job burnout needs to be relieved with emotional incentive mechanisms.

Care for the elderly is a national strategy, we currently await relevant policies regarding care for the elderly to be issued by the state (Reference point 2). Improving care for frail older adults remains a national priority. Since many adverse health outcomes in older adults result from the interaction of multiple risk factors, multifactorial risk reduction interventions have been proposed to be more appropriate for many of the "geriatric syndromes" 28 . Multifactorial interventions have been developed for falls, incontinence, pressure ulcer prevention, behavioural disturbances, and insomnia among the elderly. Furthermore, there is a need to identify specific evidence-based practices to reduce the risk of infections in long-term care facilities.

\section{Nursing risk warning strategy in long-term care facilities}

Based on the previous theoretical framework, research, and the correlation analysis of results, a nursing risk warning model of long-term care facilities has been developed. In the model, the risk is first identified through an analysis of factors; second, risk assessment is carried out based on the identified risk factors; third, risk management measures are constructed; finally, a risk early warning strategy is formed. Based on nursing risks, risk early warning intervention measures, and challenges, the solutions (as mediating variables) that are expected to reduce the risk of care in long-term care facilities are identified.

Also, factors, as potential and observation variables, that affect nursing risks have many negative effects, such as decreasing the quality of life of the elderly, poor rehabilitation effects, associated economic compensation, decrease in the reputation of the long-term care facilities, increased psychological pressure on the nursing staff, etc. Risk assessment, training and education, and comprehensive preventive measures are the main factors that constitute risk early warning intervention measures and affect each other (Fig. 2).

There are many nursing risks in long-term care facilities, including personal problems of the elderly, management and nursing operation problems, etc. Among them, nursing risks are affected by related factors and result in adverse consequences. The early warning and intervention measures mainly include risk assessment, training, and continuing education, and comprehensive risk prevention measures. Also, there are some challenges as well as solutions, such as the lack of human resources and elderly care policies. These factors, as observational and intermediate variables, jointly affect the risk reduction of 
nursing in long-term care facilities. Nursing risk assessment plays an important intermediate role in nursing risk prevention and control. Staff training and continued education provide methodological support for risk assessment and risk prevention and control. Many participants expressed a lack of staff in nursing homes, as well as the need for training and continued education. However, nursing home care workers have limited resources to access training, which requires supportive social and national policies ${ }^{29}$. Therefore, it is necessary to promote supportive national policies for elderly care, provide training and continued education, actively respond to various challenges, strengthen management, and strengthen risk early warning and assessment, to reduce nursing risks and promote physical and mental health, and quality of life of the elderly in long-term care facilities.

\section{Limitations}

1. In this study, only long-term care facilities in Chengdu, China were included, so the extrapolation of the results was poor. Cultural and regional differences should be considered when referencing the results of this research.

2. This study did not conduct a longitudinal analysis of the results. Mixed studies can be conducted in the future to explore the mechanisms of nursing risk occurrence in long-term care facilities and the mutual effects of related factors, to better safeguard the physical and mental health of the elderly in long-term care facilities.

\section{Conclusion}

There are many nursing risk factors in long-term care facilities, among which nursing risk assessment plays an important intermediate role in risk prevention and adverse reactions. Risk prevention and control can be conducted according to the early warning model of nursing risk in long-term care facilities, which consists of risk factor identification, risk assessment, risk prevention measures, current challenges, and solutions. Comprehensive measures can then be formulated and implemented according to relevant nursing risk factors to reduce the incidence of nursing risk in long-term care facilities and promote the safety of the elderly in long-term care facilities.

\section{Declarations}

Ethics approval and consent to participate: Ethical approval was obtained from the Biomedical Ethics Committee of West China Hospital of Sichuan University (No. 2021-255), together with written informed consent was obtained from all participants. We followed the COREQ guidelines to ensure rigour in our study.

Consent for publication: All authors have read and approved the final draft, and consent for publication of our paper.

Availability of data and material: The data that supports the findings of this study are available on 
request from the corresponding author. The data are not publicly available due to privacy or ethical restrictions.

Competing interests: The authors declare no conflict of interest.

Funding: This study was supported by 71871147 from National Natural Science Foundation of China, Surface project (Feng-ying Zhang), by 2021YJ0431 from Sichuan Province Science and Technology Support Program (Chang-qing Liu), and by HXHL19052 from West China Nursing Discipline Development Special Fund Project, Sichuan University (Chang-qing Liu).

Authors' contributions: CQ L and HF R were involved in the design of this study, data collection, analysis and interpretation of data, drafting and revising the manuscript. JL L, LN C and XF X provided help with the data collection, analysis and interpretation. FY Z made substantive intellectual contributions to the interpretation of data and draft of the manuscript. The authors had read and approved the final manuscript.

Acknowledgements: We would like to express our gratitude to the long-term care facilities staff who participated in the interview, and also to the National Natural Science Foundation of China, the Sichuan Province Science and Technology Support Program and the West China Nursing Discipline Development Special Fund Project, Sichuan University, for funding. We would also like to thank Wenxing Editing Service for proofreading the article.

\section{References}

1. SUN J, JIANG X-y. The level and influencing factors of health service demand among elderly residents in long-term care facilities in Fuzhou. Chinese Journal of Nursing Education. 2016:09.

2. Gartshore E, Waring J, Timmons SJBhsr. Patient safety culture in care homes for older people: a scoping review. BMC Health Services Research. 2017;17(1):1-11.

3. Lifang Tong, Yuan Y. Research progress on safety management of elderly care in long-term care facilities. Chinese Journal of Gerontology. 2015;6(35):1710-1713. doi:10.3969/j.issn.10059202.2015.06.132

4. Porter-Armstrong AP, Moore ZE, Bradbury I, McDonough S. Education of healthcare professionals for preventing pressure ulcers. Cochrane Database of Systematic Reviews. 2018;(5)

5. Baumgarten M, Margolis DJ, Localio AR, et al. Pressure ulcers among elderly patients early in the hospital stay. The Journals of Gerontology Series A: Biological Sciences Medical Sciences. 2006;61(7):749-754.

6. Onder G, Carpenter I, Finne-Soveri $\mathrm{H}$, et al. Assessment of nursing home residents in Europe: the Services and Health for Elderly in Long TERm care (SHELTER) study. BMC Health Services Research. 2012;12(1):1-10. 
7. Dai Qingmei CL, Xueyan X. Research progress of nursing risk management. Chin Nursing Management. 2006;6(8):36-38.

8. Comondore VR, Devereaux P, Zhou Q, et al. Quality of care in for-profit and not-for-profit nursing homes: systematic review and meta-analysis. Bmj. 2009;339

9. Denise Blanchard R, AdvDipTT M, Sharon Bourgeois R, FCN F. Tailored Interventions to Overcome Identified Barriers to Change: Effects on Professional Practice and Health Care Outcomes: A Review Synopsis. Cochrane Database Syst Rev 2010; (3):CD005470 doi: 101002/14651858CD005470pub2.

10. Charmaz K. Constructing grounded theory. sage; 2014.

11. Francis JJ, Johnston $M$, Robertson $C$, et al. What is an adequate sample size? Operationalising data saturation for theory-based interview studies. Psychology. 2010;25(10):1229-1245.

12. Park $\mathrm{H}$, Satoh $\mathrm{H}$, Miki A, et al. Medications and fall risk: A case-control study in nursing home residents in Japan. Aging Clinical Experimental Research. 2020;32(5):885-892.

13. Emily H. European pressure ulcer advisory Panel, national pressure injury advisory Panel and Pan pacific pressure injury alliance. Prevention Treatment of Pressure Ulcers/Injuries: Clinical Practice Guideline EPUAP/NPIAP/PPPIA 2019;

14. Lavallée JF, Gray TA, Dumville J, Cullum N. Barriers and facilitators to preventing pressure ulcers in nursing home residents: A qualitative analysis informed by the Theoretical Domains Framework. International Journal of Nursing Studies. 2018;82:79-89.

15. Gravenstein S, Davidson HE, Taljaard M, et al. Comparative effectiveness of high-dose versus standard-dose influenza vaccination on numbers of US nursing home residents admitted to hospital: a cluster-randomised trial. The Lancet Respiratory Medicine. 2017;5(9):738-746.

16. Vikström S, Grönstedt HK, Cederholm T, et al. A health concept with a social potential: an interview study with nursing home residents. BMC Geriatrics. 2020;20(1):1-10.

17. Toot S, Swinson T, Devine M, Challis D, Orrell M. Causes of nursing home placement for older people with dementia: a systematic review and meta-analysis. International Psychogeriatrics. 2017;29(2):195-208.

18. Wang S-Y, Shamliyan TA, Talley KM, Ramakrishnan R, Kane RLJAog, geriatrics. Not just specific diseases: systematic review of the association of geriatric syndromes with hospitalization or nursing home admission. Archives of Gerontology Geriatrics. 2013;57(1):16-26.

19. Vikström S, Grönstedt H, Cederholm T, et al. Experiences of supporting older persons in completion of an exercise and nutrition intervention: an interview study with nursing home staff. BMC Geriatrics. 2021;21(1):1-11.

20. Zha $\mathrm{C}$, Wang $\mathrm{P}, \mathrm{Hu} \mathrm{H}$, Huang $\mathrm{H}$, Wei $\mathrm{F}$, Zhang M. Analysis on the status quo of nursing safety risk cognition of 221 elderly people in long-term care facilities. Journal of Nursing Science. 2018;25((21)):40-42.

21. Shen L, Dai A. Application of Choking and Food Nursing Risk Management in Elderly Care Institutions. Chinese Journal of Health and Nutrition. 2019;29((8)):228-229. . 
doi:10.3969/j.issn.1004-7484.2019.08.286

22. Moncada LVV, Mire LG. Preventing falls in older persons. American family physician. 2017;96(4):240247.

23. Clemson L, Singh MAF, Bundy A, et al. Integration of balance and strength training into daily life activity to reduce rate of falls in older people (the LiFE study): randomised parallel trial. Bmj. 2012;345

24. Beeckman D, Clays E, Van Hecke A, Vanderwee K, Schoonhoven L, Verhaeghe S. A multi-faceted tailored strategy to implement an electronic clinical decision support system for pressure ulcer prevention in nursing homes: a two-armed randomized controlled trial. International Journal of Nursing Studies. 2013;50(4):475-486.

25. Daly T, Szebehely M. Unheard voices, unmapped terrain: Care work in long-term residential care for older people in Canada and Sweden. International Journal of Social Welfare. 2012;21(2):139-148.

26. GjødsbøI IM, Koch L, Svendsen MN. Resisting decay: On disposal, valuation, and care in a dementia nursing home in Denmark. Social Science Medicine. 2017;184:116-123.

27. Lee $Y$, Lee J, Cho M, et al. ORAL PRESETATION.

28. Colon-Emeric CS, McConnell E, Pinheiro SO, et al. CONNECT for better fall prevention in nursing homes: results from a pilot intervention study. Journal of the American Geriatrics Society. 2013;61(12):2150-2159.

29. Chen Y, Ge W, Wu S. Study on the status and influencing factors of safe drug use in 440 elderly people in long-term care facilities in Ningbo. Rehabilitation Medicine in China. 2017;26((5)):548-551. doi:10.13517 / j.carol carroll nki CCM. 2017.05.045.

\section{Tables}




\section{Table 1 Interview outline}

\section{Serial Questions number}

$1 \quad$ What do you think are the main nursing risks at present?

$2 \quad$ Has there been a risk incident in your institution? What are the risk events? What caused the risk? Please give an example.

$3 \quad$ What do you think should be included in nursing risk assessment?

$4 \quad$ Does your organization have a nursing risk assessment? If so, how do you evaluate it?

5 Once the event of nursing risk occurred, what kind of loss or negative impact will the institution, nursing staff, or the elderly suffer?

6 Do the institution have training in the assessment, response, and management of nursing risks? If so, what are the forms and the main contents?

$7 \quad$ What measures should your organization take to minimize losses?

$8 \quad$ What are the challenges and problems in nursing risk management? How could it be better? 


\section{Table 2 The related nodes of nursing risks and factors in long-term care facilities}

\section{Domain $\square \quad$ Nursing risks and factors}

- Nursing risks

falling or fall from bed

choking or aspiration

pressure ulcer

medication error

getting lost

acute critical illness

suicide or self-injury

scald or trauma

nursing operation

nursing errors
N

- $\nabla$ Influencing factors

42 decreased physical function

15 environmental impact

11 low awareness of risk

9 caregivers' awareness of risk assessment

8 lack of professionals and knowledge

6 busywork due to the shortage of nursing manpower

6 concurrent disease

6 management oversight

5 nurse inexperience

3 low level of acceptance of caregiver theory / knowledge training

fracture

3 compliance of the elderly

sudden death

3 family support

compliance of the elderly and their

family members with nursing activities

3 care time loophole

3 cognitive dysfunction

3 mental disorder (e.g., depression)

2 caregiver's sense of responsibility and patience

2 the quality of nursing operation

transhipment

2 emergency care capacity

occupational exposu
needle stick injuries)

drawing tube

1 drug effect

an abnormal state of excretion (abnormal bowel and urine)

1 delays in the development of information systems

1 hardware defect

communication

1 checks on negligence

the authority of
is insufficient 


\begin{tabular}{|c|c|c|c|}
\hline $\begin{array}{l}\text { environmental risks (light, temperature, } \\
\text { and humidity, etc.) }\end{array}$ & 1 & obesity & 1 \\
\hline acute infectious diseases & 1 & $\begin{array}{l}\text { low compliance with paid psychological } \\
\text { interventions }\end{array}$ & 1 \\
\hline seasonal diseases & 1 & caregiver's critical thinking & 1 \\
\hline low family support & 1 & family intervention & 1 \\
\hline intravenous treatment & 1 & high self-esteem of the elderly & 1 \\
\hline $\begin{array}{l}\text { strained human relations among the } \\
\text { elderly }\end{array}$ & 1 & lack of relevant professional training & 1 \\
\hline damage nurse & 1 & unreasonable human resources arrangement & 1 \\
\hline sleep disorder & 1 & no medical examination before admission & 1 \\
\hline unsound endowment insurance & 1 & improper use of materials & 1 \\
\hline dietary health & 1 & & \\
\hline medication without prescription & 1 & & \\
\hline hospital infection & 1 & & \\
\hline limited expression of the elderly & 1 & & \\
\hline
\end{tabular}

\section{Domain $\square \quad$ Risk early warning intervention measures}

\section{- $₫$ Risk assessment}

usage scale

living self-care ability

falling or drop from bed

pressure injury

cognitive

medical history and physical examination list

admission assessment for the elderly

professional and dynamic assessment

intelligence

actionability

environment

anxiety and depression mood
N

\section{- $₫$ Training /education}

22 theoretical study

17 clinical operation

15 field exercise

9

12 contingency plan

8

11 communication 5

9 problem reporting procedures

9 examination and evaluation

6 relevant regulation

4

5 further study outside the facility

4 case analysis

3 retrospective reflection

2 check

1 


\begin{tabular}{|c|c|c|c|}
\hline suicide and self-harm evaluation & 2 & nursing ethics & 1 \\
\hline hand hygiene and nosocomial infection & 2 & nursing human resource & 1 \\
\hline medication situation & 1 & nursing staff awareness and philosophy & 1 \\
\hline the economic benefits & 1 & corporate culture & 1 \\
\hline clinical experience & 1 & use of facilities and equipment & 1 \\
\hline choking cough & 1 & food sanitation & 1 \\
\hline $\begin{array}{l}\text { evaluate regularly (e.g. every three } \\
\text { months) }\end{array}$ & 1 & fire drills & 1 \\
\hline social participation ability & 1 & & \\
\hline incontinence & 1 & & \\
\hline thrombosis & 1 & & \\
\hline language ability & 1 & & \\
\hline level of care & 1 & & \\
\hline for the staff & 1 & & \\
\hline family members & 1 & & \\
\hline - $\triangle$ Consequences & $\mathbf{N}$ & - $₫$ Preventive measures & $\mathbf{N}$ \\
\hline psychological pressure & 13 & strengthening communication & 24 \\
\hline economic compensation & 12 & strengthening management & 18 \\
\hline medical staff performance & 10 & timely evaluation & 10 \\
\hline disease prognosis & 9 & prevention of various complications & 8 \\
\hline quality of life of the elderly & 9 & $\begin{array}{l}\text { collaboration of multidisciplinary teams } \\
\text { (doctors, nurses, nursing assistants, } \\
\text { administrators, the elderly, and their family } \\
\text { members) }\end{array}$ & 7 \\
\hline treatment experience and feeling & 8 & accompanied by caregivers & 7 \\
\hline long-term care facilities' reputation & 6 & induction training & 7 \\
\hline $\begin{array}{l}\text { the elderly family members' } \\
\text { satisfaction and trust }\end{array}$ & 6 & take notes and dispose on time & 7 \\
\hline perceived decline & 2 & psychological comfort & 6 \\
\hline psychological shadow of the elderly & 2 & get timely medical attention & 6 \\
\hline $\begin{array}{l}\text { extend the length of hospital stay and } \\
\text { increase the cost }\end{array}$ & 2 & Safety protection & 6 \\
\hline
\end{tabular}




\begin{tabular}{|c|c|c|c|}
\hline the doctor-patient relationship & 2 & strengthen patrol & 6 \\
\hline medical disturbance events & 2 & strengthen continuing education and training & 6 \\
\hline a change in dress and appearance & 1 & early risk warning and prevention & 5 \\
\hline empathic harm to caregivers & 1 & standardized process formulation & 5 \\
\hline year-end appraisal assessment & 1 & hardware facilities optimization & 5 \\
\hline assessment decision & 1 & panel discussion & 5 \\
\hline body pain & 1 & case analysis & 5 \\
\hline increase the nursing workload & 1 & improve the quality of care & 4 \\
\hline \multirow[t]{12}{*}{ self-care ability } & 1 & buying insurance & 3 \\
\hline & & $\begin{array}{l}\text { establishing rewards and punishment } \\
\text { mechanisms }\end{array}$ & 3 \\
\hline & & $\begin{array}{l}\text { strengthening the safety consciousness of the } \\
\text { elderly, guardians, and medical staff }\end{array}$ & 3 \\
\hline & & timely reporting & 2 \\
\hline & & support of family members & 2 \\
\hline & & dangerous goods control & 2 \\
\hline & & supervision of department & 1 \\
\hline & & make good use of the law & 1 \\
\hline & & set goals & 1 \\
\hline & & $\begin{array}{l}\text { sympathy and visiting the elderly patients in } \\
\text { hospital }\end{array}$ & 1 \\
\hline & & checking the doctor's orders regularly & 1 \\
\hline & & economic compensation & 1 \\
\hline
\end{tabular}

Domain $\square$ Challenges and solutions

- $₫$ Problems /obstacles

quality of caregivers

scarce human resources for elderly care

low risk awareness

nursing staff are poorly paid

nursing staff are lost
N

- $₫$ Solution

3 human resource development

3 national policy support

2 first aid knowledge training

2 establishing a complete training system

2 nationally certified nursing assistants

Page $18 / 20$ 


\begin{tabular}{|c|c|c|c|}
\hline changes in the spectrum of disease & 1 & reinforce responsibility consciousness & 1 \\
\hline $\begin{array}{l}\text { family members have little knowledge } \\
\text { of common diseases of the elderly }\end{array}$ & 1 & $\begin{array}{l}\text { increase the pay and treatment of nursing } \\
\text { staff }\end{array}$ & 1 \\
\hline customer compliance & 1 & step by step practice & 1 \\
\hline $\begin{array}{l}\text { the elderly individual situation (e.g., } \\
\text { aging) }\end{array}$ & 1 & $\begin{array}{l}\text { communicate and discuss with family } \\
\text { members of the elderly to strengthen ideas } \\
\text { and knowledge }\end{array}$ & 1 \\
\hline lack of standards in training content & 1 & & \\
\hline $\begin{array}{l}\text { promotion and application of new } \\
\text { technology }\end{array}$ & 1 & & \\
\hline $\begin{array}{l}\text { the formation of the endowment } \\
\text { concept of the combination of medical } \\
\text { care and health care for the aged }\end{array}$ & 1 & & \\
\hline $\begin{array}{l}\text { the medical hardware facilities } \\
\text { optimization }\end{array}$ & 1 & & \\
\hline hospital infection management & 1 & & \\
\hline
\end{tabular}

\section{Figures}

22 nursing homes and Geriatrics department of hospital in Chengdu, China

16 pension institutions were included and interviewed (including 28 participants: 18 managers, 5 head nurses, 2 qualified nurses, and 3 healthcare assistants).

\section{Figure 1}

\section{Inclusion and exclusion process of interviewees}




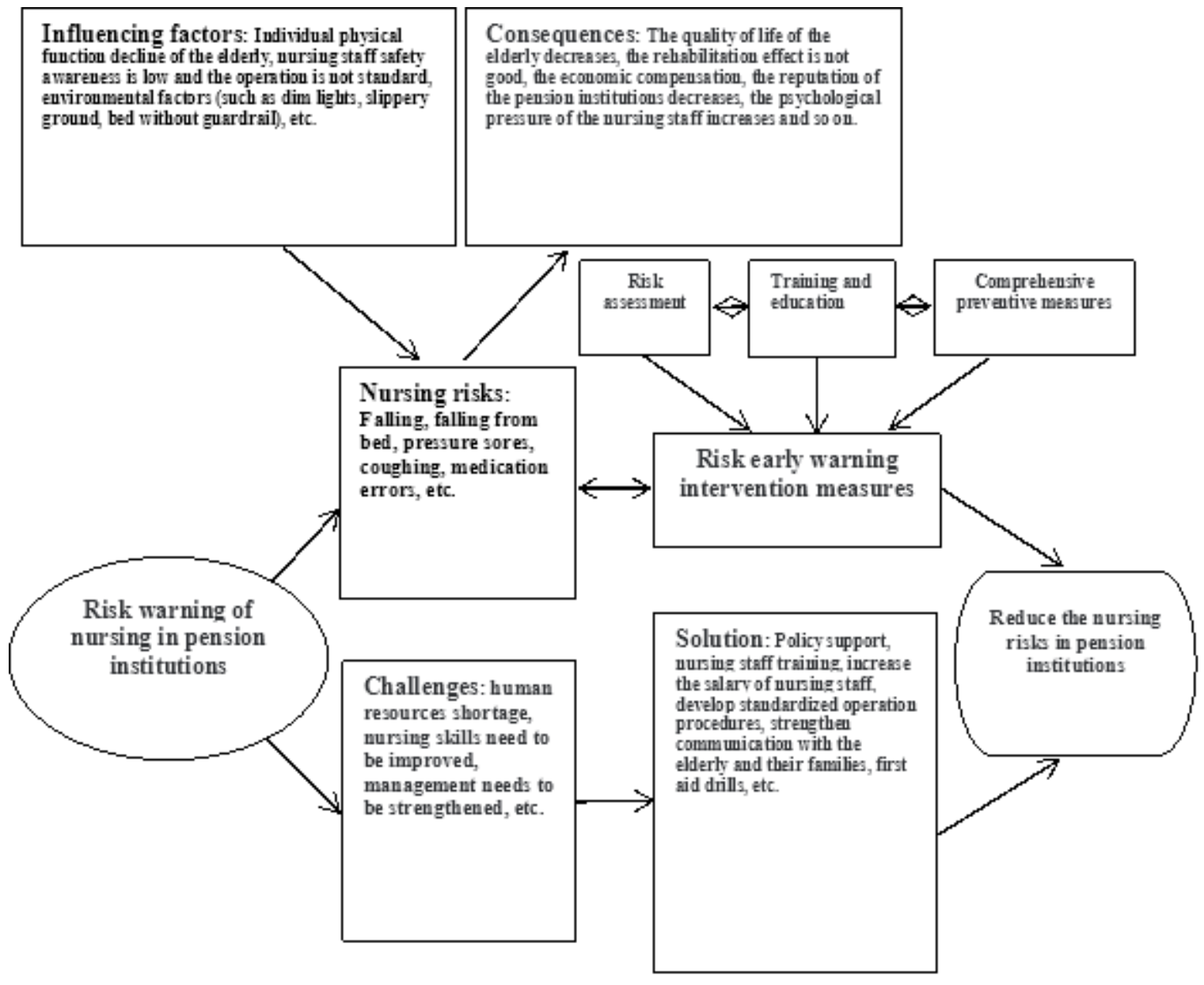

Figure 2

Risk warning model of nursing in long-term care facilities 